\title{
Patterns and predictors of isolated oculomotor nerve palsy recovery following mild traumatic brain injury
}

\author{
Sudha Menon ${ }^{1 *}$, Girish Menon ${ }^{2}$, Lakshmiprasad G ${ }^{3}$, Neetha I R K ${ }^{4}$ \\ ${ }^{\mathbf{1}}$ Assistant Professor, ${ }^{2}$ Professor, ${ }^{\mathbf{3}}$ Associate Professor, ${ }^{1,4}$ Dept. of Ophthalmology, ${ }^{2,3}$ Dept. of Neuro Surgery, KMC, Manipal, \\ Karnataka, India
}

\section{Article Info}

Received: $3^{\text {rd } J u n e, ~} 2019$

Accepted: $23^{\text {rd }}$ July, 2019

Published Online: $9^{\text {th }}$ September, 2019

Keywords: Oculomotor nerve palsy, Traumatic head injury.

\begin{abstract}
Introduction: Oculomotor nerve palsy following mild traumatic brain injury is uncommon. The exact pathogenesis, management protocol and outcome of such patients is unclear in the absence of large series. This article attempts to analyze the patterns of injury and recovery in a series of twenty one patients with third cranial nerve palsy following mild traumatic brain injury (TBI).
\end{abstract}

Materials and Methods: All patients admitted with mild head injury and third nerve involvement were included in the study. This retrospective study covered a three-year period from January 2015 to December 2017. Mild head injury was defined as patients with a Glasgow Coma score of 14 -15 and having a normal CT scan at admission. The clinical profile of the injury and recovery of the oculomotor nerve were jointly evaluated and followed up in the department of neurosurgery and ophthalmology.

Results: Our study group included twenty one patients. Levator palpebrae superioris involvement with ptosis $(95.23 \%)$ was the most consistently affected third nerve function followed by extraocular muscles $(90.47 \%)$ and pupillary fibers $(80.9 \%)$. Ptosis was partial in 11 patients and complete in nine. Of the extra ocular muscles, the most common muscles to be involved were the inferior rectus and the medial rectus which were involved in 19 patients $(90.47 \%)$. Superior rectus involvement was seen in 13 patients and inferior oblique in nine patients. Imaging including thin section CT scans (all patients) and FIESTA MRI sequence (2 patients) did not reveal any significant abnormality. All our patients were managed conservatively. Steroids and corrective surgery was not tried in any patient. On follow up, after a mean period of 6 months, partial ptosis recovered completely while complete ptosis recovered only in four patients $(44.4 \%)$. Of the seventeen patients with pupillary involvement, pupillary size and reaction improved in four $(23.5 \%)$ and remained static in 13 patients. Of the extraocular muscles superior rectus (9/13) and inferior oblique (6/9) appeared to have a better recovery than inferior rectus (09/19) and medial rectus (08/19).

Conclusion: Isolated oculomotor nerve palsy following minor head injury is uncommon. The exact pathogenesis is unclear. Advanced MRI sequences may reveal structural lesions along the course of the third cranial nerve in few cases. Pupillary fibers are most susceptible to injury and have the least rate of recovery. Partial ptosis recovers well. Recovery of extraocular muscle paresis is inconsistent. Management is essentially symptomatic and the outcome is unpredictable.

\section{Introduction}

Common causes of oculomotor nerve palsies, other than congenital palsies, include aneurysms, trauma, migraine, post-natal trauma, infection, diabetes mellitus and neoplasms. ${ }^{1}$ Isolated oculomotor nerve palsy following traumatic brain injury is most commonly noted after severe head injury with a reported incidence varying from $2-15 \% .^{2-7}$ Oculomotor nerve palsy following mild traumatic brain injury in patients with intact sensorium and normal computerized tomography (CT) scan is uncommon. The exact pathogenesis, management protocol and outcome of such patients is unclear in the absence of large series. This article discusses a series of twenty one patients with traumatic third nerve palsy and tries to discuss the clinical outcome.

\section{Materials and Methods}

The case records and radiological images of all patients with third nerve palsy admitted with mild TBI in the neurosurgery department at Kasturba Medical College, Manipal in the three-year period from Jan 2015 to Dec 2017 were analysed. The patients were jointly evaluated and followed up in the department of neurosurgery and ophthalmology. Inclusion criteria included all patients with mild head injury (GCS 1415) on admission and having a normal CT scan at admission.

*Corresponding Author: Sudha Menon, Assistant Professor, Dept. of Ophthalmology, KMC, Manipal, Karnataka, India

Email: neuron1967@yahoo.co.in

http://doi.org/10.18231/j.ijceo.2019.082 
Isolated third nerve palsy implied patients having no evidence of any other cranial nerve deficit involved in ocular movements namely the trochlear and abducent nerve. All the patients were managed conservatively and none of the patients received steroids or any form of corrective surgery.

\section{Results}

During the study period extending over three years 3756 patients were admitted with head injury of varying severity of whom 921 patients had mild head injury. The study group included 21 patients having isolated third nerve palsy amongst these 921 patients $(02.2 \%)$. The study cohort included 14 males and 07 females with a mean age of 40.63 years. Road traffic accident was the most common cause of head injury (93\%). Complete oculomotor nerve was seen in nine patients and the rest had varying degrees of third nerve involvement. Levator palpebrae superioris involvement was seen in 20 patients $(95.23 \%)$, eleven of whom had partial ptosis, nine had complete ptosis. Only one patient did not have any ptosis. Extra ocular muscle involvement was observed in all but two patients $(90.5 \%)$. Of the extra ocular muscles, the most common muscles to be involved were the inferior rectus and the medial rectus which were involved in nineteen patients. Superior rectus involvement was seen in thirteen patients and inferior oblique in nine patients. Pupillary involvement with non-reactive or sluggish reactive pupils and internal ophthalmoplegia was seen in seventeen patients $(80.9 \%)$ (Table 1). Imaging including thin section CT scans (all patients) and FIESTA MRI sequence (2 patients) did not reveal any significant abnormality. All our patients were managed conservatively Steroids and corrective surgery was not tried in any patient. On follow up, after a mean period of 6 months, partial recovery of ptosis was observed in four of the nine patients with complete ptosis. Of the eleven patients with partial ptosis all had near total recovery. Of the seventeen patients with pupillary involvement, pupillary size and reaction improved in four and remained static in 13 patients. Extra ocular movements failed to improve in six and the remaining patients had varying degrees of improvement of extra ocular movements. Of the extraocular muscles superior rectus (9/13) and inferior oblique (6/9) appeared to have a better recovery than inferior rectus (09/19) and medial rectus (08/19).

Table 1: Showing the pattern of differential involvement and recovery of the various groups of muscles supplied by the third nerve

\begin{tabular}{|l|c|c|}
\hline $\begin{array}{l}\text { Structure } \\
\text { involved }\end{array}$ & Involvement & Recovery \\
\hline $\begin{array}{l}\text { Levator } \\
\text { Palpebrae }\end{array}$ & $20(95.23 \%)$ & $15(75.0 \%)$ \\
\hline Partial ptosis & $11(55 \%)$ & $11(100 \%)$ \\
\hline Complete & $09(45 \%)$ & $04(44.4 \%)$ \\
\hline Nil $01(5 \%)$ & -- \\
\hline \multicolumn{3}{|l|}{} \\
\hline $\begin{array}{l}\text { Pupillary } \\
\text { fibers }\end{array}$ & $17(80.95 \%)$ & $4(23.5 \%)$ \\
\hline
\end{tabular}

\begin{tabular}{|l|c|c|}
\hline \multicolumn{3}{|l|}{} \\
\hline $\begin{array}{l}\text { Extra ocular } \\
\text { muscles }\end{array}$ & $19(90.47 \%)$ & \\
\hline Inferior rectus & $19(100 \%)$ & $09(47.3 \%)$ \\
\hline Medial Rectus & $19(100 \%)$ & $08(42.1 \%)$ \\
\hline Superior rectus & $13(68.4 \%)$ & $09(69.2 \%)$ \\
\hline Inferior oblique & $09(47.3 \%)$ & $06(66.6 \%)$ \\
\hline
\end{tabular}

Table 2: Ocular involvement in comparison with other studies

\begin{tabular}{|c|c|c|c|}
\hline Study & Ptosis & $\begin{array}{c}\text { EO Muscle } \\
\text { Involvement }\end{array}$ & $\begin{array}{c}\text { Pupil } \\
\text { Involvement }\end{array}$ \\
\hline Lin et al & $70 \%$ & $65 \%$ & $100 \%$ \\
\hline Kuo et al & $80 \%$ & $100 \%$ & $100 \%$ \\
\hline Nagaseki et al & $33.3 \%$ & $33.3 \%$ & $100 \%$ \\
\hline Present series & $95.23 \%$ & $90.47 \%$ & $81 \%$ \\
\hline
\end{tabular}

Table 3: Recovery pattern of third nerve palsy in comparison with other studies

\begin{tabular}{|c|c|c|c|}
\hline & \multicolumn{3}{|c|}{ Recovery Rates of } \\
\hline Study & Ptosis & $\begin{array}{c}\text { Extraocular } \\
\text { movements }\end{array}$ & Pupil \\
\hline Lin et al & $95 \%$ & $83 \%$ & $50 \%$ \\
\hline Kuo et al & $100 \%$ & $60 \%$ & $50 \%$ \\
\hline Tokuno et al & $78 \%$ & $44 \%$ & $20 \%$ \\
\hline $\begin{array}{c}\text { Present } \\
\text { series }\end{array}$ & $75 \%$ & $68.4 \%$ & $23.5 \%$ \\
\hline
\end{tabular}

\section{Discussion \\ Incidence}

The exact incidence of oculomotor nerve palsy following traumatic brain injury is unclear. Rucker and Richards report a $15 \%$ incidence of traumatic third nerve palsy in their study involving head injury patients of all grades of severity. ${ }^{89}$ In contrast, most of the other reported series quote a much lower incidence. Solomon et al in their series of 2100 patients with head injury in a tertiary trauma center report a $1.2 \%$ incidence of isolated direct third nerve palsy..$^{10}$ Similarly Memon and Paine reported a $1.1 \%$ incidence of direct third nerve palsy in their series of 1100 head injury patients..$^{11}$ Most of these cases of third nerve palsy were secondarily related to an expanding hematoma or uncal herniation due to raised intracranial pressure. ${ }^{10,11}$ In both the studies there were no cases of isolated third nerve palsy attributable to mild head. In contrast, trochlear nerve palsy and abducens palsy is more common occur after minor head trauma. This is probably due to their long intracranial course and a fragile connection to the brain stem. ${ }^{7,12}$ In comparison to trochlear and abducens nerve palsies, presence of an oculomotor nerve palsy is usually secondary to brain herniation and indicates increased severity of injury. ${ }^{13}$

Available literature on traumatic oculomotor nerve palsy following mild head trauma is restricted to few case series, the largest amongst them being by Lin et al. ${ }^{6}$ Lin et al. excluded six patients with sphenoid fractures from their original series of 26 patients to compile a series of 20 patients who had traumatic oculomotor nerve palsy following mild 
head injury with no structural abnormalities on CT scan. ${ }^{6}$ Coello et al analyzed 16440 patients with mild head injury (Glasgow coma scale 13-15) and found that only seven had oculomotor nerve palsies, seven had trochlear nerve palsies and eight had abducens nerve palsies. ${ }^{14}$ Tiffin et al did not find any patient with traumatic third nerve palsy in their study on acquired cranial nerve palsies of varying aetiologies conducted over a nine-year period. ${ }^{15}$ Our series of 21 patients $(02.2 \%)$ thus, is one of the largest series of isolated third nerve palsy following mild traumatic brain injury.

\section{Signs and Symptoms}

The presenting features of oculomotor nerve palsy include ptosis, paresis of extraocular movements and pupillary dilatation. Internal ophthalmoplegia with pupillary involvement seems to the most consistent observation in published series. ${ }^{6,14,15}$ Occasionally post traumatic pupilsparing oculomotor palsy can result from infarction of the oculomotor nerve. This is more common in patients with diabetes mellitus. Similarly, a miotic pupil may be seen in patients with an associated Horners syndrome. In Lin's series, all 20 patients $(100 \%)$ had internal ophthalmoplegia, 14 (70\%) had ptosis, and 13 (65\%) had extraocular palsy. ${ }^{6}$ Kuo et al made a similar observation in their series of 10 cases where all had pupillary involvement, 8 had ptosis, 9 had complete loss of extraocular movements and one had partial restriction with inferior rectus palsy. ${ }^{5}$ In Nagaseki et al's series of 6 cases, all had pupillary involvement and only two had partial extraocular palsies and ptosis. ${ }^{16}$ Oculomotor nerve palsy may also be present with mydriasis, blepharoptosis, near phorias in association with convergence insufficiency. These patients may not have other obvious features of oculomotor nerve palsy and phorias should be assessed with cover-uncover testing in all patients before excluding third nerve palsy. Phorias generally resolve and improve over time. ${ }^{6}$ Our findings are similar to that in other series with $90 \%$ patients having extraocular muscle paresis, $81 \%$ having pupillary involvement and $95.2 \%$ having ptosis. (Table 2)

\section{Pathophysiology}

The exact pathophysiology of oculomotor palsy in mild head injury with normal CT scans is unclear. Traumatic oculomotor palsy can be caused by direct or indirect injury to the oculomotor nerve. ${ }^{17}$ Indirect injury occurs when an expanding lesion like blood clot or brain oedema causes uncal herniation which results in third nerve compression. This usually affects the cisternal segment and is seen in severe head injury. Direct injury can be anywhere along the course of the oculomotor nerve and include - third nerve nucleus in the midbrain, intrafascicular part in the midbrain, at the nerve exit zone from the midbrain, in the cisternal segment, in the sphenocavernous region, the orbital apex and within the orbit.

Direct injury affecting the midbrain will result in features of nuclear third nerve palsy and a poor neurological grade. The distance the oculomotor nerve travels after its exit from brainstem is one of the shortest route among the nerves passing through the superior orbital fissure. Heinze 1 in an autopsy investigation of cranial nerve injuries suggested the following mechanism for third nerve damage - contusion necrosis with softening of the proximal extramedullary nerve trunk, intraneural and perineural hemorrhage at the superior orbital fissure, and nerve rootlet avulsion and damage at the exit site from the midbrain. ${ }^{18} \mathrm{He}$ proposed that the differential movement between the brainstem and supratentorial structures and the resultant shearing injury on the third nerve is the likely pathology. ${ }^{18}$ During its course, the third nerve runs over the tough posterior petroclinoid ligament. It is likely to be stretched at this point when the brain stem shifts downwards at the moment of impact . ${ }^{19-21}$ Internal ophthalmoplegia results due to injury to the pupillomotor fibers on the ventromedial surface of the third nerve at this point because this acts as the fulcrum during the downward displacement of the brainstem. ${ }^{22,23}$

The third nerve may also suffer from disturbances in blood supply secondary to head injury. Few authors believe that a pre-existing structural abnormality like an occult mass lesion is necessary for third nerve to get affected following mild head injury. ${ }^{11,20,24-26}$ Walter et al reported a case where in a third-nerve palsy after mild head trauma was associated with an underlying posterior communicating artery aneurysm..$^{25}$ Jacobson et al report a case where post traumatic nerve palsy was associated with an arteriovenous malformation compressing the nerve. ${ }^{27}$ These mechanisms although plausible are extremely rare and we did not have any such patients in our series.

\section{Imaging}

In indirect-type injuries, the underlying pathology like brain oedema or brain hemorrhage can often be diagnosed with relative ease on imaging studies. However, in direct-type oculomotor injuries, only subtle findings may be noted on imaging. CT scan will seldom show any abnormality except for occasional thin fracture lines along the margins of the superior orbital fissure. Magnetic resonance imaging (MRI) may show the presence of stretch injury in the dorsal midbrain or dot haemorrhages at the site of exit of the oculomotor nerve. MRI may also pick up bending of the oculomotor nerve at the posterior petroclinoid ligament, and enhancement of the cisternal portion of the oculomotor nerve. ${ }^{15,22,27-29}$ Magnetic resonance angiography may reveal the presence of a posterior communicating artery aneurysm if present. Diffusion tensor imaging (DTI) if available may show petechial cerebral hemorrhages that spared the brainstem. ${ }^{29}$ Partial sectioning of the oculomotor nerve just before entering the superior orbital fissure can be detected by Diffusion tensor imaging fiber tracking of the oculomotor nerve where it is seen as a sharp arrest of oculomotor fibers at this precise point. ${ }^{29}$ In our series CT scan including thin section orbital cuts failed to reveal any significant radiological abnormality. MRI was done in only two patients and did not pick up any abnormality.

\section{Management}

Treatment for complete oculomotor nerve palsy is often challenging both from a cosmetic and a functional point of view. As observed by Miller et al there is no satisfactory surgical treatment for patients with complete 3rd nerve palsy. Ptosis, diplopia, accommodation deficits, phorias can all be extremely disabling and stressing. ${ }^{6,21}$ Few patients who 
develop amblyopia may never have adequate improvement of visual acuity.

Management is essentially expectant and symptomatic. Steroid usage has been reported in a few cases of direct injury with inconsistent varying results. ${ }^{6,23}$ Similarly botulinum toxin injection has been found to be beneficial in selected patients. A few patients have also been managed with occluding cosmetic contact lenses to prevent diplopia as a temporary measure until recovery. Patients with evidence of bony compression may benefit from surgical decompression. ${ }^{6}$ Strabismus surgery and ptosis surgery is considered when there is no further improvement but is usually delayed up to 6 to 12 months after the trauma. Spontaneous recovery is rare but possible and it is prudent to wait for at least six months before strabismus surgery. ${ }^{30}$ All our patients were managed conservatively.

\section{Outcome}

The prognosis of total traumatic oculomotor palsy is unpredictable. Spontaneous recovery is possible but full recovery is seldom seen. ${ }^{5,16,29,30}$ Lin et al showed a 14-month recovery rate of $95 \%$ for ptosis, $83 \%$ for extra-ocular muscle paresis, and $50 \%$ for pupillary involvement. ${ }^{6}$ Kuo et al reported a recovery rate of $100 \%$ for ptosis, $60 \%$ for extra ocular muscle involvement and $50 \%$ for the pupil in the ten patients that they studied. ${ }^{5}$ Tokuno et al reported an improvement of the levator function in 78\%, the extra ocular movements in $44 \%$ and pupil function in $20 \% .{ }^{31}$ Partial oculomotor nerve palsy can resolve in one to three months as happened in eleven of our patients. Our findings are similar to that of multiple authors who have observed that recovery rate of ptosis is higher than that of external ophthalmoplegia and pupillary fibers. In our study recovery of ptosis (75\%) was higher than the extra ocular movement recovery $(68.4 \%)$ and the recovery of the pupillary fibers $(23.5 \%)$. (Table 3 ) No definitive prognostic factor has been established except for Park et al's observation that the initial deviation angle is the only prognostic factor associated with complete recovery. ${ }^{32}$

\section{Conclusion}

Isolated oculomotor nerve palsy following minor head injury is uncommon. The exact pathogenesis is unclear and advanced MRI sequences may reveal structural lesions along the course of the oculomotor nerve in few cases. Pupillary fibers are most susceptible to injury and have the least rate of recovery. Partial ptosis recovers well. Recovery of extraocular muscle paresis is inconsistent. Management is essentially symptomatic and the outcome is unpredictable.

\section{Source of Funding: None.}

\section{Conflict of Interest: None.}

\section{References}

1. Dong Bee Kook, Byung Ho Park, Euna Hwang, Chung Hun Kim. Traumatic Oculomotor Nerve Palsy. Arch Plast Surg. 2015;42(2);250-2.
2. Odebode TO, Ademola-Popoola DS, Ojo TA, Ayanniyi AA. Ocular and visual complications of head injury. Eye. 2005;19:561-66.

3. Van Stavern GP, Biousse V, Lynn MJ, Simon DJ, Newman NJ. Neuro-ophthalmic manifestations of head trauma. $J$ Neuroophthalmol. 2001;21:112-7.

4. Kaido T, Tanaka Y, Kanemoto Y, Katsuragi Y, Okura H Traumatic oculomotor nerve palsy. J Clin Neurosci. 2006; 13:852-5.

5. Kuo LT, Huang AP, Yang CC, Tsai SY, Tu YK, Huang SJ. Clinical outcome of mild head injury with isolated oculomotor nerve palsy. J Neurotrauma. 2010;27:1959-1964.

6. Lin C, Dong Y, Lv L, Yu M, Hou L. Clinical features and functional recovery of traumatic isolated oculomotor nerve palsy in mild head injury with sphenoid fracture. J Neurosurg. 2013;118:364-9.

7. Li G, Zhu X, Gu X, Sun Y, Gao X, Zhang Y, Hou. Ocular movement nerve palsy after mild head trauma. World Neurosurg. 2016;94:296-302.

8. Richards BW, Jones FR, Young BR. Causes and prognosis in 4278 cases of paralysis of the oculomotor, trochlear and abducens cranial nerves. Am J Ophthalmol. 1992;113:489-96.

9. Rucker CW. Paralysis of the third, fourth and sixth cranial nerves. Am J Ophthalmol. 1958;46:787-94.

10. Solomons NB, Solomon DJ, DeVilliers JC. Direct traumatic third nerve palsy. S Afr Med J 1980; 58:109-11.

11. Memon MY, Paine KWE. Direct injury of the oculomotor nerve in craniocerebral trauma. J Neurosurg. 1971;35:461-4.

12. Kwartz J, Leatherbarrow B, Davis H. Diplopia following head injury. Injury 1990;21:351-2.

13. Dhaliwal A, West AL, Trobe JD, Musch DC. Third, fourth, and sixth cranial nerve palsies following closed head injury. $J$ Neuroophthalmol. 2006;26:4-10.

14. Coello AF, Canals AG, Gonzalez JM, Martin JJ. Cranial nerve injury after minor head trauma. J Neurosurg. 2010;113:54755 .

15. Tiffin MacEwen CJ, Craig EA, Clayton G. Acquired palsy of the oculomotor, trochlear and abducens nerves. Eye. 1996;10:377-84.

16. Nagaseki Y, Shimizu T, Kakizawa T,Fukamachi A, Nukui H. Primary internal ophthalmoplegia due to head injury. Acta Neurochir(Wien). 1989;97:117-22.

17. Lakshmiprasad G Traumatic Oculomotor Neuropathies following mild head injury. World Neurosurg. 2017;98:853-5.

18. Heinze Cranial nerve avulsion and other neural injuries. Med J Aust 1969;2: 1246-9.

19. Mariak Z, Mariak Z, Stankiewicz A. Cranial nerve II-VII injuries in fatal head trauma. Eur J Ophthalmol. 1997;7:68-72.

20. Eyster EF, Hoyt WF, Wilson CB. Oculomotor palsy from minor head trauma. JAMA. 1972;220:1083-6.

21. Muthu P, Pritty P. Mild head injury with isolated third nerve palsy. Emerg Med J. 2001;18:310-1.

22. Berti AF, Ramirez PM, Tran HP. MRI findings of oculomotor nerve palsy in mild traumatic brain injury: case report and review of literature. J Neurol Res. 2013;3:163-5.

23. Liu YT, Lee YC, Liu HC. Isolated oculomotor nerve palsy due to head injury. J Chin Med Assoc. 2004;67:149-51.

24. Kanski, J. J., Bowling, B., Nischal, K. K., \& Pearson, A. (2011). Clinical ophthalmology: A systematic approach (7th ed.). Edinburgh; New York: Elsevier/Saunders.

25. Walter KA, Newman NJ, Lessell S. Oculomotor palsy from minor head trauma: initial sign of intracranial aneurysm. Neurol 1994;44:148-50.

26. Chen CC, Pai YM, Wang RF, Wang TL, Chong CF. Isolated oculomotor nerve palsy from minor head trauma. Br J Sports Med. 2005;39:e34. 
27. Jacobson DM, Warner JJ, Choucair AK, Ptacek LJ. Trochlear nerve palsy following minor head trauma. A sign of structural disorder. J Clin Neuroophthalmol 1988;8:263-68.

28. Balcer LJ, Galetta SL, Bagley LJ, Pakola SJ. Localization of traumatic oculomotor nerve palsy to the midbrain exit site by magnetic resonance imaging. Am J Ophthalmol. 1996;122:4379.

29. Jacquesson T, Frindel C, Cotton F. Diffusion Tensor Imaging Tractography Detecting Isolated Oculomotor Nerve Damage After Traumatic Brain Injury. World Neurosurg. 2017;100:707.e5-707.e7

30. Schumacher-Feero LA, Yoo KW, Solari FM, Biglan AW. Third cranial nerve palsy in children. Am J Ophthalmol. 1999;128:216-21.

31. Tokuno T, Nakazawa K, Yoshida S, Matsumoto S, Shingu T, Sato S, Ban S, Yamomoto T. Primary oculomotor palsy due to head injury: Analysis of ten cases. No Shinkei Geka. 1995;23:497-501.

32. Park UC, Kim SJ, Hwang JM, Yu YS. Clinical features and natural history of acquired third, fourth, and sixth cranial nerve palsy. Eye. 2008;22:691-6.

How to cite this article: Menon S, Menon G, Lakshmiprasad G, Neetha I R K. Patterns and predictors of isolated oculomotor nerve palsy recovery following mild traumatic brain injury. Indian $J$ Clin Exp Ophthalmol 2019;5(3):343-7. 